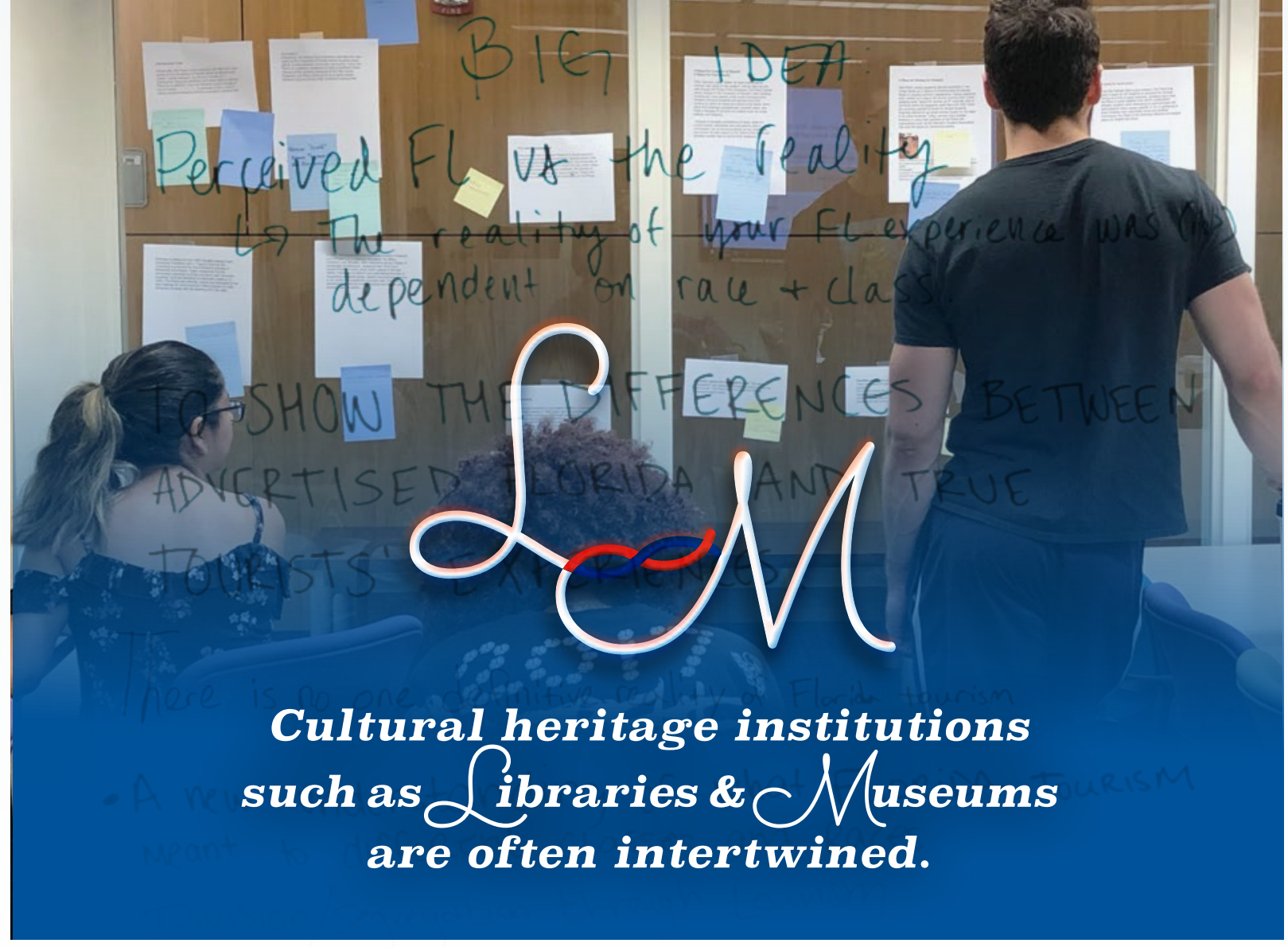

\title{
TRAINING MUSEUM PROFESSIONALS IN THE LIBRARY
}

Authors: Lourdes Santamaría-Wheeler, Exhibits Director Elizabeth Bouton, Exhibits Associate

Though the University of Florida (UF) does not offer any degrees in Library and Information Science, it offers a competitive program in Museum Studies (MS) that grants a Master of Arts or Graduate Certificate.

\footnotetext{
he Museum Studies program and the George A. Smathers Libraries have been informally working together for many years. Historically, students from Museum Studies have interned, volunteered, and conducted thesis projects in the campus Libraries. More recently, Library faculty have employed these students to conduct preservation assessments, facilitate collection inventories and re-housing in Special Collections, create interpretive signage for historic buildings, assist in grant writing research, and co-curate exhibitions. As library-collecting practices increasingly incorporated non-archival items such as three-dimensional objects, Master of Science students provide valuable skills in processing and storing such items. The Libraries' Exhibits Director is also adjunct faculty for the program and regularly teaches seminar courses that address cultural heritage practices more broadly.
} 

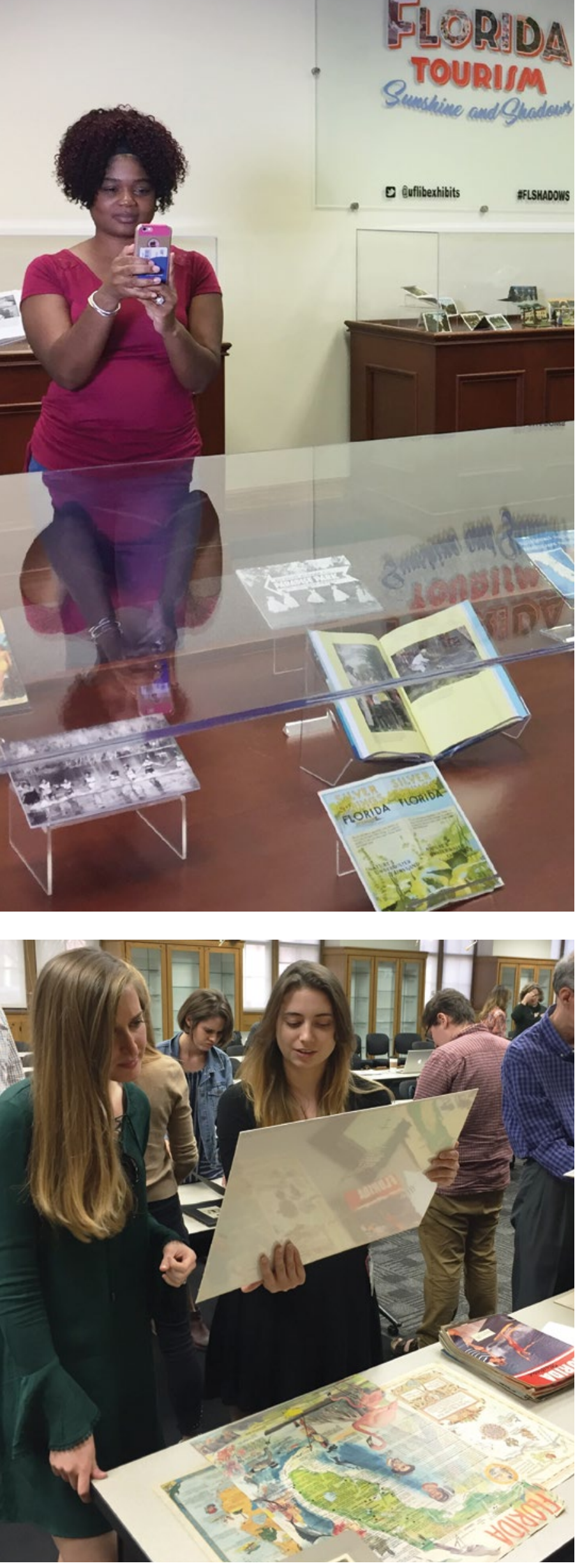

The partnership is mutually beneficial and signals a broader trend in cultural heritage professions and GLAM (Gallery, Library, Archive, Museum) collaboration. As emerging museum professionals, the students gain valuable experience that can help focus their career path. The Libraries benefit from the students' expertise and willingness to experiment. More often than not, these opportunities are paid assignments, which is rare in both the library and museum field.

Paid individual students often work behind the scenes and thus their efforts are less known to the public. For a more visible result, recent course collaborations best illustrate the growing relationship.

In Spring 2017, the Director of Museum Studies (Briley Rasmussen) and the Libraries' Exhibits Director (Lourdes Santamaría-Wheeler) co-taught the Exhibitions Seminar. The course was driven by student inquiry and was an experiment in collaborative exhibition development processes. The course included 13 students, from across disciplines, who were enrolled in the Museum Studies MA or certificate program. The students were tasked with researching in Special \& Area Studies Collections, focusing on an aspect of Florida tourism. Divided into specific group roles, they developed a physical and online exhibition with accompanying publicity and educational materials. The result was Florida Tourism / Sunshine and Shadows. Presented in the Smathers Library Gallery October 13, 2017 -December 14, 2017, Florida Tourism examined the social and racial inequities of tourism in Florida from the late 19th century to 1971, when Walt Disney World opened. It was the first student-curated exhibit in the 
Libraries since the creation of the Exhibits Program in 2012. It was also the first time an exhibit developed from a theme rather than a collection. While this collaboration may seem typical at other universities, it is unique in the level of autonomy and access students were given.

Drawing on the success of the course and the exhibition, the class was again taught by Santamaría-Wheeler in Spring 2019. For the newest iteration of the course, students were grouped by exhibit topic interest, rather than the whole class working on the same exhibition. The smaller group sizes allowed individuals to experience multiple aspects of exhibition development while still going beyond curatorial duties. Proposed exhibitions drew from Special \& Area Studies Collections and focused on the Panama Canal during World War II, the Everglades, and University of Florida History. Such broad topics allowed students to focus on aspects that interested them while still answering the question of why it should matter to visitors.

All three exhibits were successfully developed and will be presented in Smathers Library in the coming months. The first exhibit, The Plaza of the Americas: A Place For...,

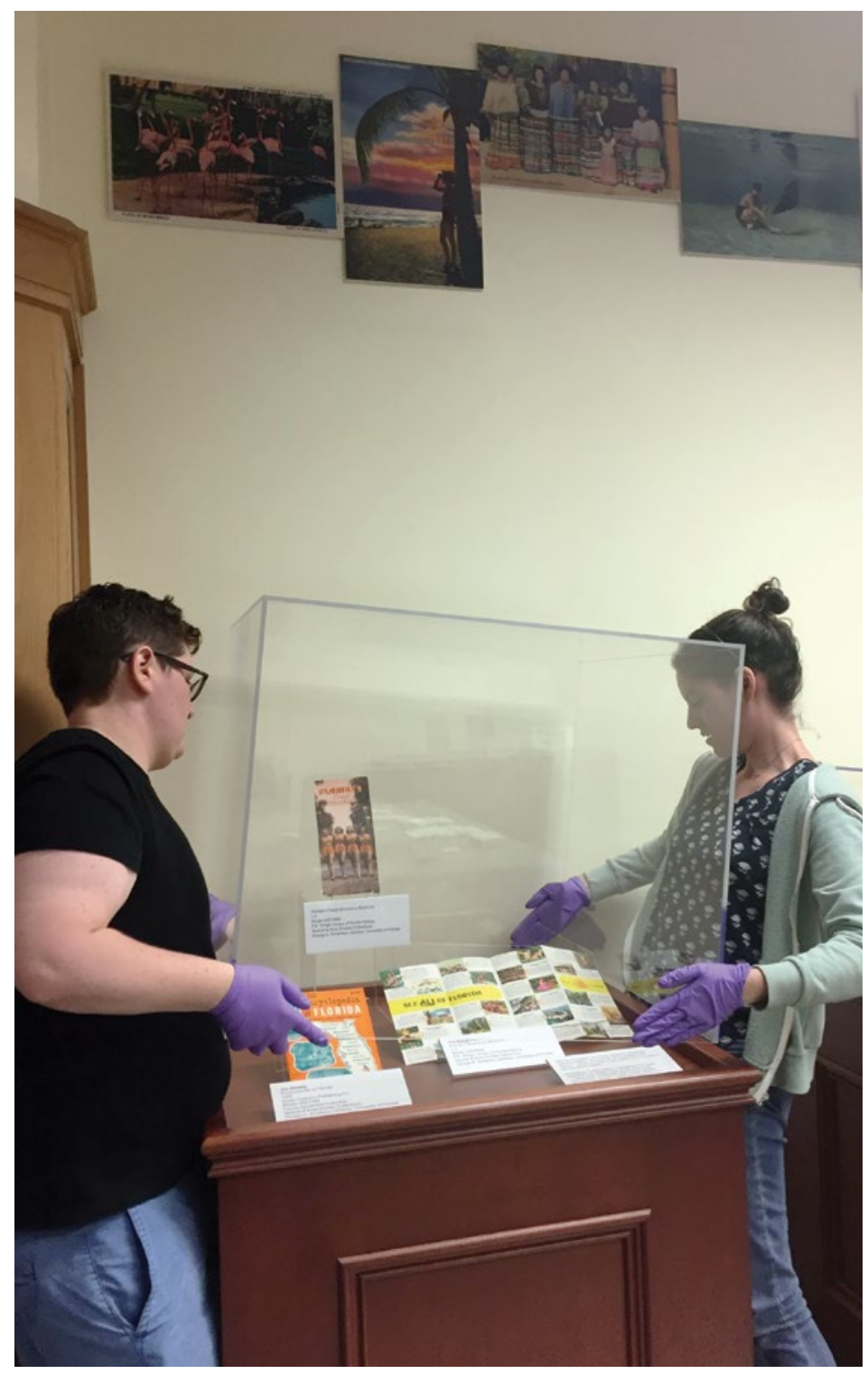

examines the iconic Plaza of the Americas (located just steps from the exhibit gallery) as a transformative space for students on campus. The exhibit will be on view Fall 2019 in the Smathers Gallery, on the second floor of Smathers Library. This is a fitting timeframe, as new students arriving on campus are likely unfamiliar with campus history.

Also on view in Smathers Gallery will be Ladies of the Everglades. This exhibit looks at environmental conservation efforts that led to the creation of Everglades National Park. In particular, it will focus on the work of May Mann Jennings, Marjory Stoneman 
